\title{
Fullerene Black: Structure, Properties and Possible Applications
}

\author{
S.D. Kushch* ${ }^{*}$ N.S. Kuyunko ${ }^{\dagger}$ \\ The Institute of Problems of Chemical Physics, Russian Academy of Sciences, Akademician \\ Semenov Ave. 1, Chernogolovka, Moscow oblast, 142432 Russia
}

(Received 13 June 2012; published online 21 August 2012)

\begin{abstract}
This review concerns the fullerene black, a poorly known nano-sized carbon material, the insoluble residue after extraction of fullerenes from fullerene soot produced by arc evaporation of carbon material (usually graphite) in a helium atmosphere. This by-product of the production of fullerenes, whose yield reaches $80 \mathrm{wt} \%$, is a finely dispersed material with a particle size of $40-50 \mathrm{~nm}$. It includes amorphous carbon, graphitized particles, and graphite. Test reactions showed the presence in the structure of fullerene black of curved surfaces, and, like fullerenes, of alternating non-conjugated simple and double bonds. In addition to the double bonds, its structure includes dangling bonds in the concentration not higher than one per 1200 carbon atoms. This nano-carbon can not be graphitized, enters into the reactions of nucleophilic addition, and absorbs oxygen and water from the atmosphere. The fullerene black as was shown activate hydrogen and thus to undergoes to a hydrogenolysis without a catalyst and to catalyzes the dehydrogenation and dehydrocyclization of alkanes. This carbon nanomaterial can be used as a sorbent for organics, as a catalyst support, as a tribotechnical additive; and it can interact with carbide-forming metals and reinforces their surface.
\end{abstract}

Keywords: Fullerene black, Non-conjugated bonds, Adsorption.

The fullerene black is the insoluble residue after extraction of fullerenes from the product of electric arc or laser evaporation of carbon material (usually graphite). On the one hand, fullerene black is the main component of the evaporation product, its yield exceeds 50\% per an evaporated carbon. On the other hand, it is a byproduct, a waste of fullerenes production. Many publications and patent are focused on the fullerenes, their chemistry, physics, unusual properties and on their possible, often fantastic, applications, while the main product is marked as unnecessary, which, unfortunately, is unavoidable. The fullerene black as an object of study is described only in a small number of articles. This review concerns the structure, chemical properties, and potential applications of fullerene black and is designed to draw attention to this relatively low cost carbon nanomaterials.

Fullerene black is a black fine powder with low bulk density (0.03-0.05 $\left.\mathrm{g} \cdot \mathrm{cm}^{-3}\right)$, specific surface $300 \mathrm{~m}^{2} \cdot \mathrm{g}^{-1}$ $\left(\mathrm{BET} / \mathrm{N}_{2}\right)$ and the particle size of $40-50 \mathrm{~nm}$ (Fig. 1), which follows from the data of electron microscopy [1,2].

Fullerene black is not a homogeneous substance: it contains amorphous carbon, graphitized particles, and graphite. As recently presumed the fullerene black contains structures with curved graphene layers [2], graphitized particles with planar benzoid rings, and graphite [3]. x-Ray amorphous carbon is determined by broadened halo at $2 \theta=11 \div 32^{\circ}$. Both graphitized particles and graphite are expressed by narrow reflection at $2 \theta=26.2^{\circ}$. According to the elemental analysis, fullerene black contains $91-93 \%$ wt. of carbon, 1-2\% of hydrogen, and 6 $8 \%$ of oxygen. Hydrogen is contained in the form of difficultly removable water [1]. The surface layers of fullerene black, according to XPS data, are concentrated by oxygen and contain C $91.0 \%$ and $\mathrm{O} 8.8 \%$.

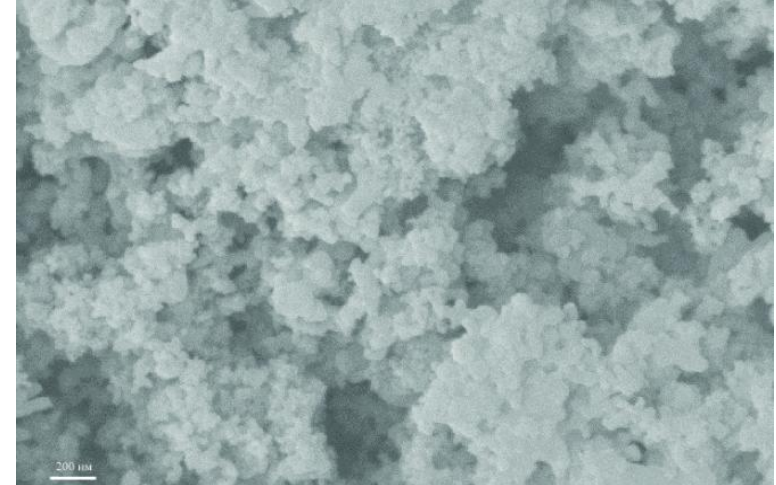

Fig. 1 - Fullerene black SEM image

As was shown by test reactions typical for alkenes [1] alternating double and simple bonds present in the fullerene black structure. The double bonds are nonconjugated: fullerene black reacts only with dienes, but not with dienophiles [4]. A fullerene black can be brominated, but in contrast to the usually formed dibromoalkanes, the fullerene black bromoderivative is a brominating agent [1]. At boiling in hypochlorous acid at $156^{\circ} \mathrm{C}$ fullerene black loses $\geq 77 \%$ wt. in $1 \mathrm{~h}$ [3], but the products composition is not known. The fullerene black, like fullerenes, does not interact with a electrophilic reagents HX type as hydrogen halides. This nanocarbon, like fullerenes, is an electron-deficient alkene, and enters into the nucleophilic addition reaction that are not typical for simple alkenes. A heating fullerene black in aqueous base solution (sodium hydroxide or carbonate, or pyridine) yields the hydroxy derivative [6] mentioned in our work [1]. Fullerene black at heating in air with ethanolamine forms a cyclic adduct [6]. [60] Fullerene interacts with $\mathrm{NaOH}$ in the

\footnotetext{
*ksd@icp.ac.ru

$\dagger$ arbuzovartem@yandex.ru
} 
presence of (tert-Bu $)_{4} \mathrm{NOH}$ as a catalyst with the formation of polyhydroxy-derivative [7]. The presence in fullerene black graphitized particles and graphite with conjugate system of aromatic bonds decrease its reactivity.

Probably, the absence of conjugation of the double bonds is a consequence of curvature like fullerene in the fullerene black structure. The similarity of fullerenes with fullerene black was confirmed by comparative measurements of the C1s energy in [60] fullerene and fullerene black by XPS, which showed that fullerene black like [60] fullerene is characterized basically by $\pi$-bonds with energy $284 \mathrm{eV}$. The presence of nonconjugated double bonds is also confirmed by the lower conductivity of fullerene black compared with graphite ( 0.03 against $3-5 \Omega^{-1} \mathrm{~cm}^{-1}$ for the tablet by fourcontact method).

Reactivity of fullerene black depends on the conditions of the preparation of the parent fullerene soot. We have developed $[8,9]$ the optimal conditions for production of a more active fullerene black, not containing graphite and graphitized particles. The graphite evaporation in DC arc under optimum conditions (He pressure $\geq 500$ Torr, the interelectrode distance $\geq 7 \mathrm{~mm}$ ) yields $8.3 \%$ of fullerenes and $81.0 \%$ of fullerene black; the cathode deposit is $\leq 10 \%$ per carbon evaporated. The fullerene black obtained from such fullerene soot not contains graphite and graphitized particles and includes amorphous carbon with a predominantly alternating single and double bonds. Effect of conditions of the electric arc evaporation of graphite on the content of fullerenes in the condensed products have been studied previously (e.g, [10,11]), but the properties of the product were not investigated.

In addition, the fullerene black is characterized by a singlet ESR signals with $g$-factor 2.022 [1, 12, 13], which apparently is associated with the dangling bonds, but their concentration is very low: one such bond per 1200 carbon atoms.

Recently we have shown [1, 12-14] that fullerene black absorbs $\mathrm{O}_{2}$ and $\mathrm{H}_{2} \mathrm{O}$. Dioxygen adsorption broadens the ESR signal while decreases its amplitude. The dependence of amplitude $I$ on the oxygen pressure $P$ is described satisfactorily by the equation

$$
\frac{I}{I_{0}}=\frac{n_{1}}{1+P / K_{1}}+\frac{n_{2}}{1+P / K_{2}}
$$

where $K_{i}$ and $n_{i}$ are equilibrium constant and contributions of the two sites of binding oxygen $\left(n_{1}+n_{2}=1\right)$, respectively. This suggests the existence of at least two types of oxygen adsorption by fullerene black. Both types of oxygen adsorption, as well as the sorption of water by the fullerene black, in our opinion, associate with electron-deficient feature of fullerene black and the existence in its structure of non-conjugated double bonds. Indeed, according to XPS, in the structure of fullerene black, besides the carbon-carbon $\pi$-bonds, there are $\mathrm{C}-\mathrm{O}$ and $\mathrm{C}=\mathrm{O}$ bond. The electron-deficient character of fullerene black determines the ease of addition to it of dioxygen by its unshared electron pair and water dipole by the its negatively charged end [13, 14]. A sorption of oxygen by fullerene black as recently suggested [15, 16] associates with structural defects and is controlled topochemi-cally. The adsorbed dioxygen and water can be partially desorbed in a vacuum at 150.C within $1.5 \mathrm{~h}$ or ther-mally with carbon oxides, mainly $\mathrm{CO}$, evolution. The evolution of dioxygen, water (as $\mathrm{H}_{2} \mathrm{O}, \mathrm{H}^{+}$, and $\mathrm{OH}^{-}$), and carbon oxides at the thermal desorption suggests both physical and chemical sorption of dioxygen and water. [60] and [70] Fullerenes contain in contrast to fullerene black only $\leq 1.7 \%$ wt. of oxygen. It was noted in [17] that the fullerenes, like astralenes and charcoal, adsorb oxygen physically, and the adsorption is not associated with the structure. Up to $150^{\circ} \mathrm{C}$ the weight loss of a fullerene black sample in an argon is up to $6 \% \mathrm{wt}$. According to mass spectral analysis, mainly oxygen and water are thus removed that probably were adsorbed physically. The resorption of oxygen from air by the fullerene black after the thermal desorption in argon is slow (requires more than $8 \mathrm{~h}$ ) [14]. The presence in the fullerene black structure of non-conjugated double bonds and the related to this sorption of oxygen favor the easy oxidation of fullerene black in air at a temperature up to $320^{\circ} \mathrm{C}$. The above mentioned hydroxy derivative of fullerene black is oxidized easier than the fullerene black. Graphite and graphitized particles are oxidized at higher temperatures $[1,8,9]$. The oxidation of fullerene black was studied recently [18-29], but these works were largely of phenomenological character.

Nitric oxide oxidizes fullerene black at 1273.C with the formation of a mixture of $\mathrm{N}_{2} \mathrm{O}, \mathrm{NO}_{2}, \mathrm{~N}_{2}, \mathrm{CO}$, and $\mathrm{CO}_{2}$ [25]. The standard energy of combustion of carbon particles decreases in the series: $\mathrm{C}$-atoms, $\mathrm{C}_{3}$-clusters, $\mathrm{C}_{4}$-clusters, $\mathrm{C}_{2}$-clusters, fullerene black, fullerene $\mathrm{C}_{60}$, $\mathrm{C}_{70}$, higher fullerenes, fullerene "onions," graphene stacks, and multilayer graphite [3]. Measured in [3] the standard energy of the fullerene black combustion is $36.0 \pm 0.5 \mathrm{~kJ} \cdot \mathrm{g}-1$. According to our data [12-14], for the fullerene black produced according to $[8,9]$ this value is $20 \pm 2 \mathrm{~kJ} \cdot \mathrm{g}^{-1}$.

The annealing of fullerene black in a vacuum leads to an increase in the temperature of oxidation, broadening of the ESR signal, increases electrical conductivity of the fullerene black, and transforms its ESR line into the Lorentzian one $[1,12]$. The adsorption of oxygen by the fullerene black annealed in a vacuum, as in the case of not annealed fullerene black, leads to a decrease in the intensity and ESR signal broadening, but the broadening is proportional to the $\mathrm{O}_{2}$ pressure [12]:

$$
\Delta \Delta H \approx \frac{I_{1} P}{K_{1}+P}+\frac{I_{2} P}{K_{2}+P}
$$

The changes observed in the ESR spectra, a decrease in the reactivity, and increase in the electrical conductivity of the fullerene black after annealing in a vacuum probably results from the alignment of the curved surface of the fullerene black and appearance of a system of conjugated bonds. The ESR signal of the fullerene black calcined in a vacuum at $1000^{\circ} \mathrm{C}$, in contrast to the signal of amorphous carbon obtained by decomposition of sulfanilic acid, is not broadened under the influence of oxygen [28, 29]. The thermal (500$2400^{\circ} \mathrm{C}$ ) processing of fullerene black leads to the formation of multi-layer particles of "onion" type, but no graphitization is observed [30,31]. 
The fullerene black absorbs hydrogen, whose desorption is observed at $550^{\circ} \mathrm{C}$, and at temperatures $\geq 700^{\circ} \mathrm{C}$ it undergoes to hydrogenolysis with formation of methane, ethane, and ethene in a ratio $\sim 100: 10: 1$ mol. respectively. Unlike common alkenes, the fullerene black can undergoes to the hydrogenolysis without a catalyst. The [60] fullerene was subjected to hydrogenation at a pressure of $1.0-2.5 \mathrm{MPa}$ at $400^{\circ} \mathrm{C}$, the resulting hydride decomposed at $500^{\circ} \mathrm{C}$ [32]. The fullerene black as we have shown [33-35] catalyzes the methane pyrolysis. The formation of ethane together with methane suggests that methane is activated by dissociative adsorption. In order to avoid coking and deactivation of the catalyst dilution of methane by hydrogen should applied, which sharply reduces the methane conversion [33-35]. [60] Fullerene and fullerene soot activate methane to form ethene at temperatures $\sim 600^{\circ} \mathrm{C}$ [36]. The possibility of applying fullerenes and fullerene soot under these conditions is questionable because of the sublimation of fullerenes. Application for this purpose of fullerene black which does not undergo sublimation is preferred.

The fullerene black, as shown previously [1, 37], catalyzes dehydrocyclization of $\mathrm{C}_{6+} n$-alkanes with the formation of benzene and its homologues. Unlike the conventional reforming process it does not require $\mathrm{H}_{2}$ dilution of alkane because the catalyst coking does not observe. Along with the dehydrocyclization, the produced toluene and xylenes undergo demethylation. Introduction to the catalyst of acidic component $\left(\gamma-\mathrm{Al}_{2} \mathrm{O}_{3}\right)$ transforms the monofunctional mechanism of dehydrocyclization into a bifunctional one, increases the alkane conversion and decreases demethylation and cracking (Tabl. 1) [1, 37]. The conventional catalysts of reforming also catalyze $\mathrm{C}_{6+} n$-alkanes de-hydrocyclization, but note that they include noble metals and convert alkanes only to $15-20 \%$.

Table 1 - Conversion of $n$-pentane, $n$-hexane, $n$-heptane and $n$-octane (saturated vapor at $22 . \mathrm{C}$ in argon) over the catalysts based on the fullerene black at $550^{\circ} \mathrm{C}$ and gas hour space velocity GHSV $=1000 \mathrm{~h}^{-1}$ (calculated liquid hour space velocity LHSV $=1 \mathrm{~h}^{-1}$ )

\begin{tabular}{|c|c|c|c|c|c|c|}
\hline \multirow{3}{*}{$\begin{array}{c}\text { Product } \\
\text { of conversion }\end{array}$} & \multicolumn{6}{|c|}{ Yield (\%) at $n$-alkanes conversion } \\
\hline & \multirow{2}{*}{$\begin{array}{c}n-\mathrm{C}_{6} \\
\begin{array}{c}\text { Fullerene black } \\
+ \text { quartz (1:29 } \\
\text { wt) }\end{array}\end{array}$} & \multicolumn{3}{|c|}{$n-\mathrm{C}_{7}$} & & $n-\mathrm{C}_{5}$ \\
\hline & & $\begin{array}{c}\text { fullerene black } \\
+ \text { quartz (1:29 } \\
\text { wt) }\end{array}$ & $\begin{array}{c}\text { fullerene black } \\
+\mathrm{Al}_{2} \mathrm{O}_{3}+\text { quartz } \\
\quad(1: 2: 27 \text { wt })\end{array}$ & $\begin{array}{c}\mathrm{Al}_{2} \mathrm{O}_{3}+\text { quartz } \\
\quad(1: 1 \text { wt })\end{array}$ & \multicolumn{2}{|c|}{$\begin{array}{l}n \text {-C8 } \\
\qquad \begin{array}{l}\text { fullerene black + quartz } \\
(1: 29 \mathrm{wt})\end{array}\end{array}$} \\
\hline $\begin{array}{c}\mathrm{C}_{1}-\mathrm{C}_{4} \text { Hydrocar- } \\
\text { bons }\end{array}$ & 13,7 & 25,7 & 19,5 & 1,7 & 6,4 & 8,8 \\
\hline $\mathrm{C}_{5}$ alkanes & 0,1 & 6,6 & 0,4 & 0,3 & 0,7 & 1,1 \\
\hline $\mathrm{C}_{5}$ alkenes & Сл & 3,7 & 0,1 & 0,1 & 0,5 & 1,3 \\
\hline $\mathrm{C}_{6}$ alkanes & 1,0 & 2,7 & 0,1 & 0,3 & 3,9 & - \\
\hline $\mathrm{C}_{6}$ alkenes & 1,1 & 6,2 & 0,3 & 0,15 & 1,9 & \\
\hline $\mathrm{C}_{7}$ & - & - & - & - & 19,4 & - \\
\hline Benzene $\mathrm{C}_{6} \mathrm{H}_{6}$ & 40,7 & 25,8 & 5,1 & - & 42,2 & 5,8 \\
\hline Toluene $\mathrm{C}_{7} \mathrm{H}_{8}$ & - & 7,9 & 69,4 & - & 4,8 & - \\
\hline $\mathrm{Ph}(\mathrm{Me})_{2}+\mathrm{PhEt}$ & - & - & - & - & 16,8 & - \\
\hline Arenes total & 40,7 & 33,7 & 74,5 & - & 63,8 & 5,8 \\
\hline $\begin{array}{l}n \text {-Alkane conver- } \\
\text { sion }\end{array}$ & 56.8 & 78.8 & 95,0 & $\sim 2.5$ & 96.3 & 16.6 \\
\hline
\end{tabular}

By special experiments [1, 37] have shown that at the $n$-hexane dehydrocyclization 1-hexene and cyclohexane are intermediate products. Taking into account the presence in the structure of fullerene black of non-conjugated double bonds, we can draw an analogy between the catalytic action of fullerene black and the cyclohexene disproportionation ("irreversible" catalysis [38]), particulary with respect to the cross disproportionation, where the fullerene black behaves as a hydrogen acceptor (Fig. 2). An important feature of fullerene black as compared with conventional catalysts for the reforming proceeding with dehydrocyclization of $\mathrm{C}_{6+} n$-alkanes, besides the lack of necessity to $\mathrm{H}_{2}$ dilute the raw material, is the absence of noble metals, the possibility of processing the reforming by-product as raffinate, and the formation of benzene at dehydrocyclization of $n$-pentane containing only 5 carbon atoms (Table 1 ).

Various types of coals, including wood charcoal and coke formed at the pyrolysis of the gasoline of direct distillation (naphtha), also catalyze dehydrocyclization of $n$-octane, diisobutyl (2,5-dimethylhexane) and cyclohexane at $500-560^{\circ} \mathrm{C}$ with $\mathrm{LHSV}=0.1-0.15 \mathrm{~h}^{-1}$, but the content of aromatics in the catalysate does not exceed $20 \%$ and the catalysts suffer to rapid coking [39]. Wood charcoal catalyzes the naphtha reforming to form catalysate with octane number 87 , but converts methylcyclohexane and $n$-heptane to only 15.1 and $9.6 \%$ respectively [40]. Fullerenes activate the hydrogen in the process of hydrogenation, including the hydrogenolysis of hydrocarbons [41] and the dehydrooligomerization of alkylaromatics [42]. The nucleophilic addition of and the $\mathrm{C}_{6+} n$-alkanes dehydrocyclization described for the 
fullerene black [1, 37], as well as the assumed dissociative adsorption of hydrocarbons in these processes indicate the unique properties of fullerene black such as the hydrogen activation in water, molecular hydrogen, and alkanes. An important processing feature of fuller- ene black as compared with related fullerenes is its insolubility in any solvents and the inability to sublimation at any temperature.

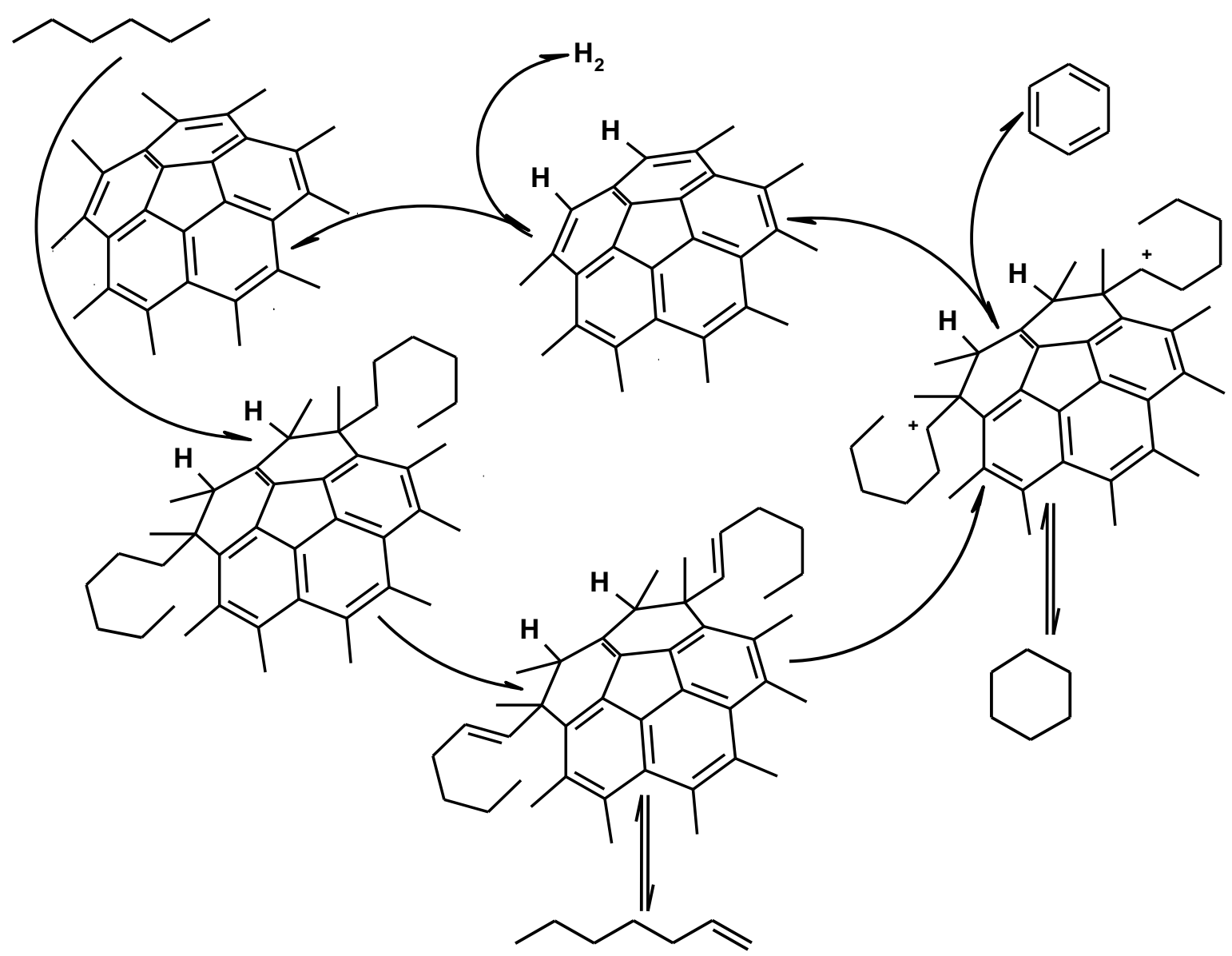

Fig. 2 - $n$-Hexane dehydrocyclization scheme

Recently we have reported [1] that the fullerene black adsorbs aromatic compounds. In particular, sorption capacity of fullerene black with respect to lubricant oil was $4.0 \mathrm{~g} / \mathrm{g}$, with respect to desalted crude oil up to $9 \mathrm{~g} / \mathrm{g}$, for $o$-dichlorobenzene $9.0 \mathrm{~g} / \mathrm{g}$. Air-dry fullerene black may include up to 70 wt \% of $o$-xylene. Similar facts have been noted for a organics vapors [43]. To improve the sorption properties of fullerene black, it can be irradiated with visible light [44] or it can be used for creation of a composite sorbent with polyacrylamide [45]. At the same time, accounting for the solubility of fullerenes in aromatic hydrocarbons, the possibility to use fullerenes or products containing them as sorbents is rather doubtful. Additives of fullerenes and fullerene soot improve mechanical, physical, chemical, and electrical properties of caprolon [46]. Tribological characteristics of Fluoroplast-4 increased by adding to it fullerene soot and fullerene black [47]. The introduction of [60] fullerene in the friction zone favors the formation of a polymer film with the major oil. Similar action shows the fullerene soot [48]. The fullerene black produced by procedures [8, 9] not containing fullerenes can be used as tribological additive [49]. The introduction of fullerene black in the oil I-40A in the amount of 0.5 to
$7.0 \%$ wt. leads to a decrease of the friction coefficient and to the formation of smooth friction surface with increased microhardness (5900-6400 MPa) and very low wear rate $\left(I_{h}=5.1 \cdot 10^{-10}\right)$. Probably the presence in the structure of fullerene black of non-conjugated double bonds favors the formation of wear-resistant structures.

At the interaction of iron metal with fullerene black in an inert atmosphere at $1140-1150^{\circ} \mathrm{C}$ iron carbide formed [50-52], as showed the thermal analysis. Iron(III) oxide is reduced by fullerene black at 620 $635^{\circ} \mathrm{C}$ and then forms iron carbide with the same endoeffect. The interaction of fullerene black with 45 steel at $1150^{\circ} \mathrm{C}$ leads to the formation on its surface of a nanostructured composite coating that includes orthorhombic iron carbide crystallites of 60-100 nm size and dispersed islands of fullerene black with a particle size of 40-50 nm. Thickness of the coating at the duration of interaction $0.5 \mathrm{~h}$ reaches $\sim 20 \mu \mathrm{m}$. Microhardness of the carbide coating is $6520 \mathrm{MPa}$, whereas for the original steel (annealed at about 400.C for $1 \mathrm{~h}$ ) it is $3200 \mathrm{MPa}$, which confirms a significant effect of the 45 steel surface hardening as a result of its interaction with the fullerene black [50-52]. Such a coating comprising sili- 
con carbide with a particle size of $20 \mathrm{~nm}$ is formed at the interaction of fullerene black with an eutectic AK12 silumin. The larger effect is achieved under the influence of fullerene black with hypereutectic KS740 silumin: in this case, along with the particles of silicon carbide with the size up to $20 \mathrm{~nm}$ the manganese carbide $\mathrm{Mn}_{3} \mathrm{C}$ is formed. It is surprising that silicon carbide that usually is formed at temperatures $\geq 960^{\circ} \mathrm{C}$, at using fullerene black is formed at a temperature of $530 \mathrm{C}$, that is, below the silumin melting temperature. Even wider range of carbides is registered in the coating created on the surface of VT-4 titanium alloy: after the reaction with fullerene black its phase composition includes the titanium carbide (TiC), the manganese carbide $\left(\mathrm{Mn}_{3} \mathrm{C}\right)$, and the aluminum carbide $\left(\mathrm{Al}_{4} \mathrm{C}_{3}\right)$ [53].

The ability of fullerene black to adsorb various organic compounds makes it a promising support for catalysts. It is also important that fullerene black is nanosized, because the fixed metal particles can not be larger than the support particles. The double bonds of fullerene black as anchored groups and $\mathrm{H}_{2} \mathrm{PtCl}_{6} \cdot x \mathrm{H}_{2} \mathrm{O}$ as a precursor were used for fixation of the catalytically active platinum. Another way of the platinum fixation on the fullerene black surface is also associated with the presence of double bonds: fullerene black is brominated, the bromine derivative is subjected to alkaline hydrolysis with the formation of hydroxy derivative of the empirical formula $\mathrm{C}_{7} \mathrm{OH}$, i.e. it contains one hydroxy group per $\sim 7$ carbon atoms. In this case, due to the replacement of acido-ligands of platinum atom and the formation of acid, an organic base (e.g., pyridine) should be added to the reaction mixture.

At the same time pyridine involves in the exchange of acido-ligands $\mathrm{Cl}^{-}$at the platinum atom and converts precursor $\mathrm{H}_{2} \mathrm{PtCl}_{6}: x \mathrm{H}_{2} \mathrm{O}$ with the platinum-containing anion into the complex $\left[\mathrm{Pt}(\mathrm{Py})_{2}\right] \mathrm{Cl}_{4}$ or $\left[\mathrm{Pt}(\mathrm{Py})_{4}\right] \mathrm{Cl}_{4}$ wherein platinum enter into the cation composition. The hydroxyl proton of the fullerene black hydroxyderivative is exchanged by platinum cation easier. The bounded aqueous solubility of di- or tetrapyridineplatinum(IV) chloride promotes platinum fixation too [54].

After fixation the platinum as $\mathrm{Pt}^{4+}$ and its reduction to the metallic $\mathrm{Pt}(0)$ by formate ion $\mathrm{HCOO}^{-}$the plati-

\section{REFERENCES}

1. S.D. Kushch, P.V. Fursikov, N.S. Kuyunko, A.V. Kulikov, V.I. Savchenko, Eurasian Chem. Techn. J. 3, 131 (2001).

2. C. Jager, Th. Henning, R. Schlögl, O. Spillecke, J. NonCryst. Solids 258, 161 (1999).

3. J.C. Scanlon, L.B. Ebert, J. Phys. Chem. 97, 7138 (1993).

4. M.T. Beck, G. Mandy, S. Papp, I. Dekany, Colloid Polymer Sci. 283, 237 (2004)

5. N. Man, Y. Nagano, T. Kiyobayashi, M. Sakiyama, J. Phys. Chem. 99, 2254 (1995).

6. S.D. Kushch, N.S. Kuyunko in Hydrogen Material Science and Chemistry of Carbon Nanomaterials (Ed. D.V. Schur, S.Yu. Zaginaichenko, T.N. Veziroglu, V.V. Skorohod) (Kiev: AHEU: 2009); p. 562.

7. J. Li, A. Takeuchi, M. Ozawa, X. Li, K. Saigo, K. Kitazawa, J. Chem. Soc., Chem. Communs. 1784 (1993).

8. S.D. Kushch, V.E. Muradyan, P.V. Fursikov in Hydrogen Material Science and Chemistry of Metal Hydrides (Kiev: ADEF-Ukraine: 2001); p. 512.

9. S.D. Kushch, V.E. Muradyan, P.V. Fursikov in Hydrogen num particles of $4-5 \mathrm{~nm}$ size are formed, as follows from the calculation with the Selyakov-Scherrer equation from the $\mathrm{Pt}(220)$ line, and it is confirmed by TEM (Fig. 3). A similar composition with the fullerene black as a support were produced recently using precursors $\mathrm{Ru}_{x}(\mathrm{CO})_{y}[55]$ or $\mathrm{Pd}\left(\mathrm{NO}_{3}\right)_{2}[56]$.

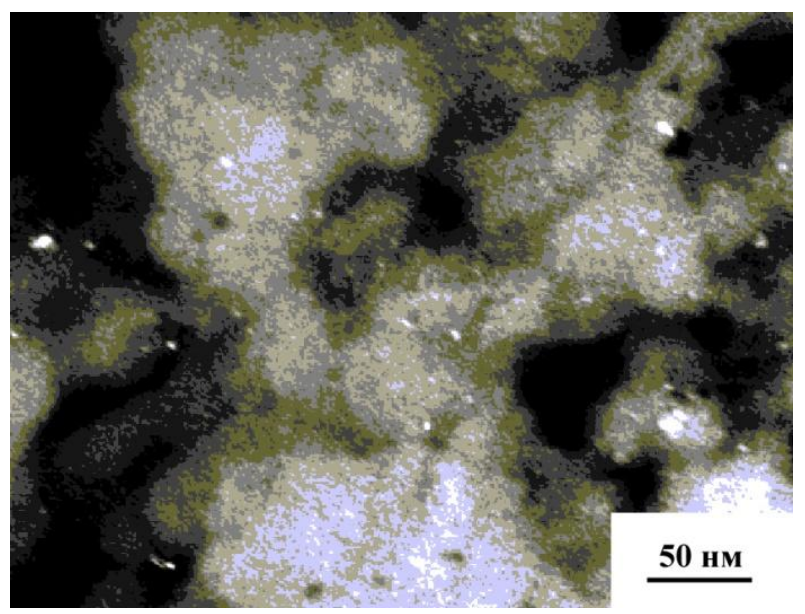

Fig. 3 - Pt/fullerene black dark-field TEM image

Pt/fullerene black compositions catalyze a model hydrogenation of dec-1-ene and nitrobenzene. Catalytic activities of $\mathrm{Pt} /$ fullerene black compositions with $\operatorname{Pt}(0)$ particle sizes of $4-5 \mathrm{~nm}$ is higher than it for conventional $\mathrm{Pt} / \mathrm{C}$ catalysts with particles size of $10-20 \mathrm{~nm}$ [49, 57].

Thus, our studies showed that fullerene black, a byproduct of the synthesis of fullerene, contains nonconjugated double bonds, a curved surface, and particles of $40-50 \mathrm{~nm}$ size, and can be used as an insoluble and non-sublimating fullerene material. The unusual properties of fullerene black such as activation of hydrogen and alkanes, sorption of oxygen and organic compounds, allow its use as a catalyst for dehydrogenation of alkanes and dehydrocyclization of $\mathrm{C}_{6+} n$-alkanes, as tribotechnical additives, as carbide-forming agent, and as a promising support for the catalysts preparation.

Material Science and Chemistry of Metal Hydrides (Kiev: ADEF-Ukraine: 2001); p. 512.

10. T. Belz, J. Find, D. Herein, N. Pfánder, Th. Rühle, H. Werner, M. Wohlers, R. Schögl, Ber. Bunsenges. Phys. Chem. 101, 712 (1997).

11. V.P. Bubnov, I.S. Krainskii, E.E. Laukhina, E.B. Yagubskii, Russ. Chem. Bull. 43, 746 (1994).

12. A.V. Kulikov, S.D. Kushch, P.V. Fursikov, V.R. Bogatyrenko, Appl. Magn. Res. 22, 539 (2002).

13. S.D. Kushch in Hydrogen Material Science and Chemistry of Carbon Nano-Materials (Ed. D.V. Schur, S.Yu. Zaginaichenko, T.N. Veziroglu, V.V. Skorohod) (Kiev: AHEU: 2007); p. 902

14. S.D. Kushch, L.N.Blinova, Russ. J. Gen. Chem. 79, 1113 (2009); Zh. Obshch. Khim. 79, 941 (2009).

15. H. Werner, M. Wohler, D. Herein, D. Bublack, J. Blöcker, R. Schögl, Fullerene Sci. Techn. 1, 199 (1993).

16. J.D. Saxby, S. Chatfield, A.J. Palmisano, A.M. Vassalo, M.A. Wilson, L.S.K. Pang, J. Phys. Chem. 96, 17 (1992). 
17. V.P. Belousov, I.M. Belousova, A.V. Ermakov, V.M. Kiselev, E.N. Sosnov, Russ. J. Phys. Chem. A. 81, 1650 (2007); [Zh. Fiz. Khim. 81, 1847 (2007)].

18. H. Werner, D. Herein, J. Blocker, B. Henschke, U. Tegtmeyer, Th. Schedel-Niedrig, M. Keil, A.M. Bradshaw, R. Schogl, Chem. Phys. Lett. 194, 62 (1992).

19. J.C. Scanlon, J.M. Brown, L.B. Ebert, J. Phys. Chem. 98, 3921 (1994).

20. T. Belz, R. Schlögl, Synth. Metals 77, 223 (1996).

21. M. Wohler, A. Bauer, R. Schlögl, Mikrochim. Acta 14, 267 (1997).

22. D.R.Huffman, Mol. Cryst. Liq. Cryst. 7, 11 (1996).

23. M. Kanowski, H.-M. Vieth, K. Luders, G. Buntkowsky, T. Belz, H. Werner, M. Wohler, R. Schlögl, Carbon 35, 685 (1997).

24. M. Egashira, H. Koura, Y. Korai, I. Mochida, J.C. Crelling, Carbon 38, 615 (2000).

25. M. Egashira, H. Koura, Y. Korai, I. Mochida, J.C. Crelling, Carbon 38, 615 (2000).

26. A.M. Huffman, J.A. Ganske, Appl. Spectr. 49, 534 (1995)

27. T. Belz, E. Sanchez, J. Yang, R. Schoonmaker, H. Sauer, J. Find, D. Herein, G. Wortmann, R. Schögl, Electrochem. Soc. Proc. 98, 169 (1999).

28. D. Heyman, Carbon 29, 684 (1991).

29. L.J. Donne, A.K. Sarkar, H.W. Kroto, J. Munn, J. Phys. Condens. Matter. 8, 2127 (1996)

30. L.J. Donne, P.F. Nolan, J. Munn, J. Phys. Condens. Matter. 9, 10661 (1997).

31. W.A. de Heer, D. Ugarte, Chem. Phys. Lett. 207, 480 (1993).

32. D. Ugarte, Carbon 32, 1245 (1994)

33. Yu.M. Shul'ga, V.M. Martynenko, B.P. Tarasov, V.N. Fokin, V.I. Rubtsov, N.Yu. Shul'ga, G.A. Krasochka N.V. Chapysheva, V.V. Shevchenko, D.V. Shchur, Fiz. Tverd. Tela 44, 522 (2002).

34. S.D. Kushch, V.E. Muradyan, P.V. Fursikov, E.I. Knerel'man, V.L. Kuznetsov, Yu.V. Butenko, Euras. ChemTechn. J. 3, 67 (2001).

35. S.D. Kushch, V.E. Muradyan, N.S. Kuyunko, Euras. Chem.Techn. J. 3, 163 (2001)

36. A.S. Hirschon, H.-J. Wu, R.B. Wilson, R. Malhotra, J. Phys. Chem. 99, 17483 (1995).

37. P.V. Fursikov, S.D. Kushch, V.E. Muradyan, G.I. Davydova, E.I. Knerel'man, A.P. Moravsky, Mol. Mat. 13, 319 (2000).

38. N.D. Zelinskii, G.I. Levi, Izv. Akad. Nauk SSSR, Otd. Khim. Nauk, 819 (1951).

39. B. Moldavskii, G. Kamusher, M. Kobyl'skaya, Zh. Obshch. Khim. 7, 1840 (1937).

40. R.A. Sanford, B.S. Friedman, Ind. Eng. Chem. 46, 2568
(1954)

41. R. Malhotra, D.S. Tse, D.F. McMillen, Patent US 5420371, (1995).

42. R. Malhotra, D.F. McMillen, D.S. Tse, D.C. Lorents, R.S. Ruoff, D.M. Keegan, Energy Fuel 7, 685 (1993).

43. V.V. Samonin, E.M. Slutsker, Russ. J. Phys. Chem. 79, 87 (2005); [Zh. Fiz. Khim. 79, 100 (2005)].

44. V.V. Samonin, V.Yu. Nikonova, E.A. Spiridonova, Russ. J. Phys. Chem. 81, 1276 (2007); [Zh. Fiz. Khim. 81, 1447 (2007)].

45. V.V. Samonin, M.L.Podvyaznikov, E.A.Spiridonova, A.Yu.Shevkina, Russ. J. Appl. Chem. 81, 1512 (2008); [Zh. Prikl. Khim. 81, 1436 (2008)].

46. M.G. Potalitsin, A.A. Babenko, O.S. Alekhin, N.I. Alekseev, O.V. Arapov, N.A. Charykov, K.V. Nekrasov, V.I. Gerasimov, K.N. Semenov, Russ. J. Appl. Chem. 79, 306 (2006); [Zh. Prikl. Khim. 79, 308 (2006)]

47. B.M. Ginzburg, D.G. Tochil'nikov, A.K. Pugachev, V.M Oichenko, Sh. Tuichiev, A.M. Leksovskii, Russ. J. Appl. Chem. 80, 1438 (2007); [Zh. Prikl. Khim. 80, 1400 (2007)].

48. D.G.Tochil'nikov, B.M.Ginzburg, Zh. Tekh. Fiz. 69, 102 (1999).

49. S.D. Kushch, N.S. Kuyunko in Uglerodnye nanostruktury, (Minsk: Lykov Institut Teplo- i Massoobmena: 2006), pp. $277,306$.

50. S.D. Kushch, N.S. Kuyunko, P.A. Vityaz', A.I. Komarov, V.I. Komarova, Russ. J. Gen. Chem. 80, 1086 (2010); [Zh. Obshch. Khim. 80, 916 (2010)].

51. P.A. Vityaz', A.I. Komarov, S.D. Kushch, V.I. Komarova, J. Frict. and Wear 31, 407 (2010); [Trenie i Iznos 31, 537 (2010)].

52. S.D. Kushch, A.I. Komarov, V.I. Komarova in Mnogofunktsional'nye materialy $v$ sovremennoyi tekhike. Materialy dlya Mikro- i Nanoelectroniki (Minsk: FTI Nat. Akad. Sci. Belarus': 2001), p. 105

53. S.D. Kushch, A.I. Komarov, V.I. Komarova in Polymernye Kompozitsii $i$ Tribologiya (Gomel': IMMS Nat. Acad. Sci. Belarus': 2009), p. 131.

54. S.D. Kushch, N.S. Kuyunko, B.P. Tarasov, Kinetics and Catalysis 50, 860 (2009); [Kinetika $i$ Kataliz 50, 895 (2009).

55. Th. Braun, M. Wohlers, T. Belz, R. Schöegl, Catal. Lett. 43, 175 (1997)

56. A. Datta, H.I. Khwaja, R.Y Kelkar, A.R. Saple, M. Datta, J. Chem. Soc., Chem. Commun. 851(1996).

57. S.D. Kushch, N.S. Kuyunko, B.P. Tarasov, Russ. J. Gen. Chem. 79, 1106 (2009); [Zh. Obshch. Khim. 79, 934 (2009)]. 